\title{
COMPLEXITY SCIENCES IN SERVICE RESEARCH - CHALLENGES AND OPPORTUNITIES
}

\author{
Göran Svensson, Oslo School of Management, Norway \\ Carmen Padin, Vigo University, Spain
}

\begin{abstract}
The objective is to provide illustration of theory from complexity sciences in service research. The performance of service encounters and the outcome of service quality are dependent upon complex and dynamic interactions between service providers and service receivers. Complexity sciences in relation to the interactive nature of the performance of service encounters and the outcome of service quality is likely to trigger and encourage innovative research designs and alternative methodological approaches to new research problems in service research. A suggestion of further research is to address where and how we can learn from other research disciplines that have explored the addressed aspects from complexity sciences in a more advanced way, and how we can transfer and incorporate these aspects and knowledge into services. The inclusion and consideration of complexity sciences in the performance of service encounters and the outcome of service quality generates a series of managerial and research implications regarding the dynamics and complexity of the interactive nature in services.
\end{abstract}

References available upon request. 